\title{
High Temperature Transformation of Tar-Asphaltene Components of Bituminous Sand Bitumen
}

\author{
Yerzhan Imanbayev ${ }^{1,3 *}$, Yerdos Ongarbayev ${ }^{1,3}$, Yerbol Tileuberdi ${ }^{1,3}$, Evgeniy Krivtsov ${ }^{2}$, Anatoly \\ Golovko' ${ }^{2}$, and Zulkhair Mansurov ${ }^{3}$ \\ ${ }^{1}$ Department of Chemistry and Chemical Technology, Al-Farabi Kazakh National University, Kazakhstan \\ ${ }^{2}$ Department of Petroleum Chemistry, Tomsk, Russia \\ ${ }^{3}$ Department of Chemistry and Chemical Technology, Institute of Combustion Problems, Kazakhstan
}

Submission: March 23, 2017; Published: April 04, 2017

*Corresponding author: Yerzhan Imanbayev, Faculty of Chemistry and Chemical Technology, Al-Farabi Kazakh National University Almaty, Kazakhstan, E-mail: erzhan.imanbayev@mail.ru

\begin{abstract}
Transformations of high-molecular-weight compounds of bituminous sands natural bitumen under the heat treatment are studied. Cracking and extraction of Kazakhstan's bituminous sand bitumen were carried out. Thermal processing of natural bitumen leads to a general change in the chemical composition of components and an increase in the output of certain factions. Molecular structures of the tar and asphaltene components of natural bitumen are built from the data of elemental analysis, 1HNMR spectroscopy and molecular weight. The content of oil, tar and asphaltenes were determined and the elemental composition of tar-asphaltene compounds was evaluated. The high molecular compounds were presented as giant molecules containing small aromatic islands with some linked by aliphatic chains.
\end{abstract}

Keywords: Natural bitumen; Asphaltene tar; Molecular structure; Fourier transform infrared spectroscopy (FTIR)

\section{Introduction}

One of the areas of increasing the resource base of hydrocarbon feedstock is the development of unconventional sources of hydrocarbons, that including natural bitumen and heavy oil, which close to bitumen on the physical-chemical properties. Over the next few decades, their role in the energy balance will increase significantly as a result of changes in the reserves of conventional petroleum to the downside and necessity for their reproduction [1]. According to the US and Canada's Geological Survey in North America hydrocarbon feedstock reserves of contained in the untraditional sources, larger than traditional reserves of oil and gas in all of the Middle East, more than 1 trillion barrels in Canada and in the United States as well. Their development while these vast reserves are a matter of great difficulty [2]. Replenish the hydrocarbon resource base through unconventional hydrocarbon material is necessary search and commercialization of cost-effective technologies for their development. Bituminous sand natural bitumen in their composition and physical-chemical properties differ significantly from conventional oils high content oftarasphaltene compounds, petroleum acids, sulfur compounds and metals as well as high density and viscosity [3]. Production methods of natural bitumen are mainly related to two issues: a) Adverse collector properties- low thermal conductivity, low permeability, lack of reservoir energy;

b) The organic part of bitumen layers is an inactive state.

The main reserve for the effective solution of this problem is study the chemical composition of heavy or high-molecularweight of petroleum component in the current refining technology $25-30 \%$ of the incoming crude oil processing and has been called "heavy oil residues". If we consider that more than half of these "residues" are so-called non-carbon components of oil or tar-asphaltene substances, it becomes clear what kind of great scientific importance and practical relevance is the problem of studying the composition, structure, properties, chemical reactions and the main areas of chemical processing and technical use of petroleum tars and asphaltenes [4]. Currently, it accumulated a considerable amount of empirical data on the molecular structure of asphaltenes, obtained with the use of chemical and physical methods. The most reliable information on the structure of asphaltenes as a whole give physical methods that allow to work out the average idea of their structure and is of great practical value. However, without the involvement of chemical methods in the case where it is necessary, instrumental 
methods cannot give a full picture of the object being studied. Research of asphaltenes chemical transformations are shown that asphaltenes components may serve as a perspective cheap natural source for practically important products for many areas of the economy. Among obtained products has radiationion exchange materials having high dynamic and kinetic characteristics, agents non-sulfur vulcanization of unsaturated rubbers, fillers, curatives and others.

Asphaltene components are in the colloidal state in highviscosity petroleum, heavy oil residues and natural bitumen. In the presence of an excess of low-molecular-weight alkenes or other non-solvents with respect, which the lyophobic tars and aromatic hydrocarbons in liquid medium is forming dispersion partially or completely dissolved then asphaltenes coagulated [5].

\section{Experimental Part}

\section{Materials}

The object of the study was collected as a sample of the bituminous sand Beke field (Kazakhstan), extract of sand and extracted asphaltenes from organic part, as well as products of their transformations during thermal processing. A distinctive feature of this field is the output of bituminous sands to the ground surface. In such reopen reservoirs and areas of active water exchange was a loss of light fractions and residual oil components were affected by various supergene factors, which led to the weighting of their composition and the formation of inactive extra heavy oil and solid bitumen $[6,7]$. Bitumen deposits occur in them in small sized lens and inter-layers. Extraction of natural bitumen from bituminous sands was carried out in Soxhlet apparatus, chloroform used as solvent. The amount of extracted natural bitumen from bituminous sands of Beke field is $12 \mathrm{wt}$. \%. The sulfur content in the bitumen is $1.5 \mathrm{wt}$. \%. Natural bitumen is characterized by low fraction content from boiling point to 200 and $350{ }^{\circ} \mathrm{C}$.

\section{Experimental procedure}

The experimental scheme of cracking process and analysis of the obtained products is given in (Figure 1).

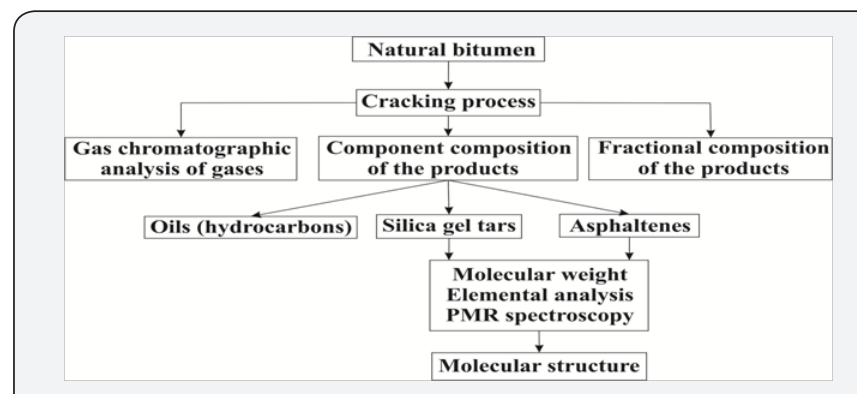

Figure1: Experimental scheme of cracking process and analysis of the obtained products.

The cracking of bitumen and study of the cracking products were described in detail in the article [6]. The molecular weight of tars and asphaltenes of natural bitumen and their cracking products measured by cryoscopic in naphthalene created in the Institute of Petroleum Chemistry on "Krion" instrument. Fourier transform infrared spectra of the tar-asphaltene components were filmed by Spectrum-65 Fourier IR spectrometer, which are used for the measurement of various organic and inorganic substances, with $\mathrm{KBr}$ cuvettes and $\mathrm{KBr}$ tablets in the range from 4000 to $400 \mathrm{~cm}-1$.

Elemental characteristics of samples were determined by elemental analyzer Vario MICRO cube (Germany). Oil samples are fed automatically into a combustion zone. Combustion gases are passing a catalytic post combustion zone and then a reduction zone, operating temperature was $1200^{\circ} \mathrm{C}$. The formed analyte gases $\mathrm{N} 2, \mathrm{H} 2 \mathrm{O}, \mathrm{CO} 2$ and $\mathrm{SO} 2$ carried by helium (He) gas are sequentially separated by a temperature programmable desorption column (TPD) and quantitatively determined on a thermo-conductivity detector (TCD). An attached computer calculates the element concentrations from detector signal and sample weight.

\section{Results and Discussion}

\section{Component composition of the products}

Table 1: Transformation of component composition of cracking products.

\begin{tabular}{|c|c|c|c|c|c|c|}
\hline \multirow{2}{*}{ Process } & \multicolumn{3}{|c|}{ Yield, wt. \% } & \multicolumn{3}{c|}{$\begin{array}{c}\text { Composition of Liquid } \\
\text { Products, Wt. \% }\end{array}$} \\
\cline { 2 - 7 } & Gas & Liquid & Coke & Oil & Tar & Asphaltenes \\
\hline $\begin{array}{c}\text { Initial } \\
\text { bitumen }\end{array}$ & 0.00 & 100.00 & 0.00 & 49.17 & 44.89 & 5.94 \\
\hline Cracking & 1.40 & 67.70 & 30.90 & 41.49 & 19.14 & 7.07 \\
\hline
\end{tabular}

Thermal upgrading of natural bitumen reduces the viscosity and tar-asphaltene components of heavy oil. Cracking process of natural bitumen leads to formation gas and liquid oil products, solid residues as coke (Table 1). Heat treatment results in increasing of oil content and the amount of bitumen highmolecular-weight components are decreased. High temperature leads to increasing formation of coke and gas as well as the destruction of tar-asphaltene components by formation light petroleum products. The content of the tars in the composition of liquid cracking products are decreased 19.14 wt. \% and the content of gas and coke after process were $1.4 \%$ and 30.9 wt. \%, respectively.

\section{Elemental characteristics of tar and asphaltenes}

Asphaltenes play an important role when the extraction and processing of heavy oil and natural bitumen. The asphaltenes are highly complex ring structures, the carbon skeleton containing naphthenic, aromatic and aliphatic hetero atomic radical cycles. Large fragments of molecules linked by bridges containing methylene groups and hetero atoms, sometimes by metals $(\mathrm{V}, \mathrm{Ni}$, Fe). The most typical substituent's cycles with a small amount of alkyl carbon atoms and functional groups, for example, oxygencontaining groups: carbonyl, carboxyl, hydroxyl and ether, and the sulfoxide group. 
Heat treatment of natural bitumen Beke field reduces the molecular weights high macromolecular components by $30 \%$ compared to initial data. It means high temperature processing directly asphaltene under similar experimental conditions, it leads to the same results: there are significant changes in the structure and properties of asphaltenes that change their phase composition. Asphaltenes loses the main feature and solubility in aromatic solvents, then change to the insoluble substances such as carbenes and cokes. According to elemental analysis (Table 2) in asphaltenes structure is reduced oxygen, sulfur content and increased content of carbon.

Table 2: Elemental composition of tar and asphaltene components

\begin{tabular}{|c|c|c|c|c|}
\hline Elements & $\begin{array}{c}\text { Initial } \\
\text { Asphaltenes }\end{array}$ & $\begin{array}{c}\text { Cracking } \\
\text { Asphaltenes }\end{array}$ & Initial Tars & $\begin{array}{c}\text { Cracking } \\
\text { Tars }\end{array}$ \\
\hline $\mathrm{C}$ & 77.30 & 81.91 & 79.70 & 81.01 \\
\hline $\mathrm{H}$ & 7.59 & 7.00 & 9.77 & 10.52 \\
\hline $\mathrm{S}$ & 1.00 & 0.64 & 0.56 & 0.26 \\
\hline $\mathrm{N}$ & 1.07 & 1.45 & 0.72 & 0.10 \\
\hline $\mathrm{O}$ & 13.04 & 9.00 & 9.26 & 8.11 \\
\hline $\mathrm{C} / \mathrm{H}$ & 10.18 & 11.69 & 8.16 & 7.69 \\
\hline $\begin{array}{c}\text { Molecular } \\
\text { weights, } \\
\text { amu }\end{array}$ & 2044 & 1304 & 751 & 499 \\
\hline
\end{tabular}

The elemental composition of tar-asphaltene components of cracking products shows a decrease hetero element content in liquid products. At high temperatures within the molecular cyclization, recombination with benzyl and heterocyclic radicals, dehydrogenation, condensation - all these processes lead to an increase in the degree of condensation and aromaticity of system. Chain transfer processes and recombination can occur between two or more asphaltene plates, which go to the formation of a cross linked insoluble product - coke. C/Hratio varies from 7.69 to 11.69 in the range $300-500{ }^{\circ} \mathrm{C}$, it is assumed that the transition to coke is carried out at a higher additional cross-linking.

\section{Infrared spectroscopy analysis of high macromolecular components}

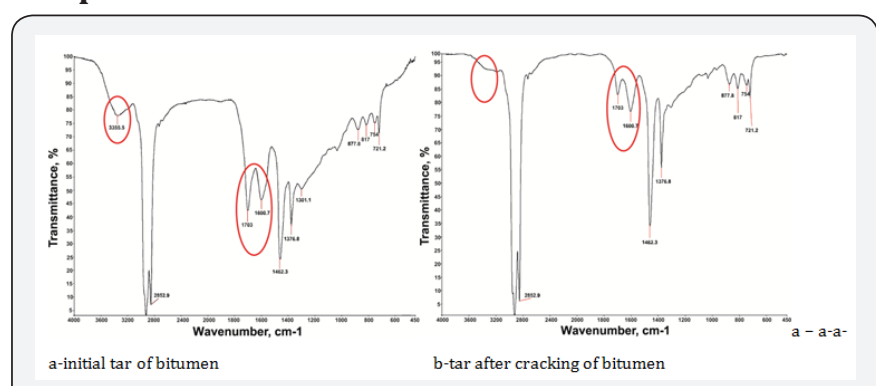

Figure 2: FTIR spectrums of tar composition of bitumen.

The chemical composition of tar and asphaltene of natural bitumen was studied by Fourier transform infrared spectroscopy (FTIR). FTIR spectrum of tars (Figure 2) peaks absorbance bands $754,817,877.8,1600.7 \mathrm{~cm}-1$ provides information condensed aromatic hydrocarbon tar structure. FTIR spectrum of the figure observed absorption band $721.2 \mathrm{~cm}-1$, characteristic of the alkyl substituent groups ( $\mathrm{CH} 3, \mathrm{CH} 2)$ with long branched structures. It should be noted (Figure 2a) a rather high intensity of the band in $1376.8 \mathrm{~cm}-1$, which belongs to the compounds of methylbenzene. Absorption band at $3355.5 \mathrm{~cm}-1$ shows the acidic hydroxyl group, absorption spectra bands 1600.7 and $1703 \mathrm{~cm}-1$ give information stretching vibrations $\mathrm{C}-\mathrm{O}-\mathrm{C}$ and $\mathrm{C}-\mathrm{OH}$ in conjunction carbonyl groups. After heating intensity peaks of these oxygen compounds of tar components were declined (Figure $2 \mathrm{~b}$ ), otherwise reduction of peaks area outcome of transformation reaction cyclic alkenes and removal of oxygen by formation water, carbon dioxide and molecular oxygen. At spectrum $1462.3 \mathrm{~cm}-1$ absorption bands belong to the stretching vibrations of methylene groups and characterize the degree of branching of paraffin compounds.

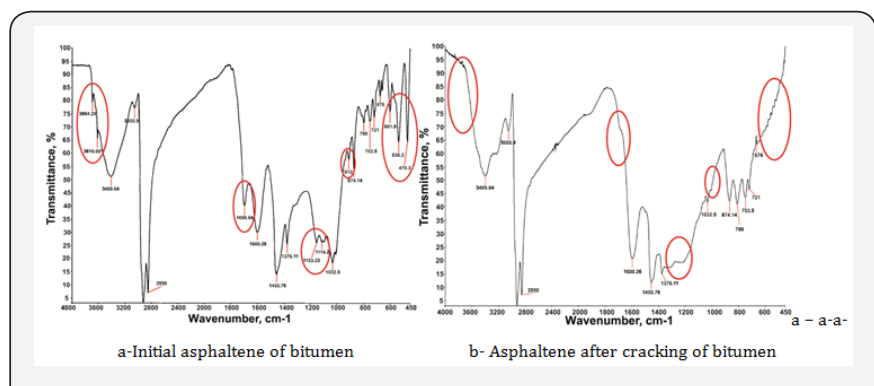

Figure 3: IR spectrums of asphaltene composition of bitumen.

Based on the obtained FTIR spectrums (Figure 3) can be concluded that having broad absorption bands in asphaltenes 3000-3700 cm-1 are characteristic for polycyclic aromatic hydrocarbons and aliphatic chains. The cracking results of bitumen (Figure 3b) clearly indicated that polycyclic aromatic hydrocarbon units were produced from asphaltene macromolecular structures and some bigger polycyclic aromatic hydrocarbon compounds have been transferred to aliphatic component to one containing shorter chains. These hydrocarbons are at the ends of free functional groups (carboxyl, carbonyl, and hydroxyl) which forming hydrogen bonds. The peaks of the initial asphaltenes (Figure 3a) absorption bands at $3694.29,3619.09 \mathrm{~cm}-1$ is due to stretching vibrations $\mathrm{OH}$ groups that actively involved in the formation of intermolecular hydrogen bonds. At the FTIR spectrum absorption bands with minimum at 2850 and $3055.9 \mathrm{~cm}-1$ which characteristic for alkyl substituent (CH3, CH2). Stretching and deformation vibrations $\mathrm{CH} 2$ and $\mathrm{CH} 3$ groups presented at absorption bands 1455.76 and $1376.11 \mathrm{~cm}-1$. As shown presence intensity bands of stretching vibrations C-O-C and in the region $1000-1200 \mathrm{~cm}-1$ is combined with intense carbonyl groups absorption bands in the 1600.26 and $1696.64 \mathrm{~cm}-1$, which $\mathrm{C}-\mathrm{OH}$ groups are missing after heat treatment of bitumen. These absorption bands are included aromatic compounds and due to the presence of hydrocarbons $\mathrm{C}=0$ groups. The absorption band in the spectrum $1032.5 \mathrm{~cm}-1$ has given information about functional group $S=0$, and it is expressed by organic form $\mathrm{RSO} 3 \mathrm{H}, \mathrm{RSO} 3$ groups. Low intensity peaks present oxygenates (1100-1300 cm-1) is not clearly allocated at this spectrum, indicating that oxygen content is low, 
while the aromatic structure $(753.5,799,874.14 \mathrm{~cm}-1)$ captured most clearly in asphaltenes spectrum. Fluctuations stretching benzene ring presented at $874.14 \mathrm{~cm}-1$ band.

Usually, thermal reactions result in the formation of highmolar-mass aromatic components in solution in the liquid phase. Reactions that contribute to this process are the cracking of side chains from aromatic groups, dimerization reactions, dehydrogenation of naphthenes (to form aromatics) and ring closure reactions (to form larger ring groups). Loss of side chains always accompanies thermal cracking. The formation of oligomers is enhanced by the presence of olefins, which themselves are products of cracking. When aromatic components reach a critical concentration, phase separation occurs to give a denser and more aromatic liquid phase. Aromaticity is the dominant factor that controls this phase separation. This observation suggests that increasing the molar mass is a significant factor in the formation of coke from bitumen.

\section{Molecular structure of tar and asphaltenes}

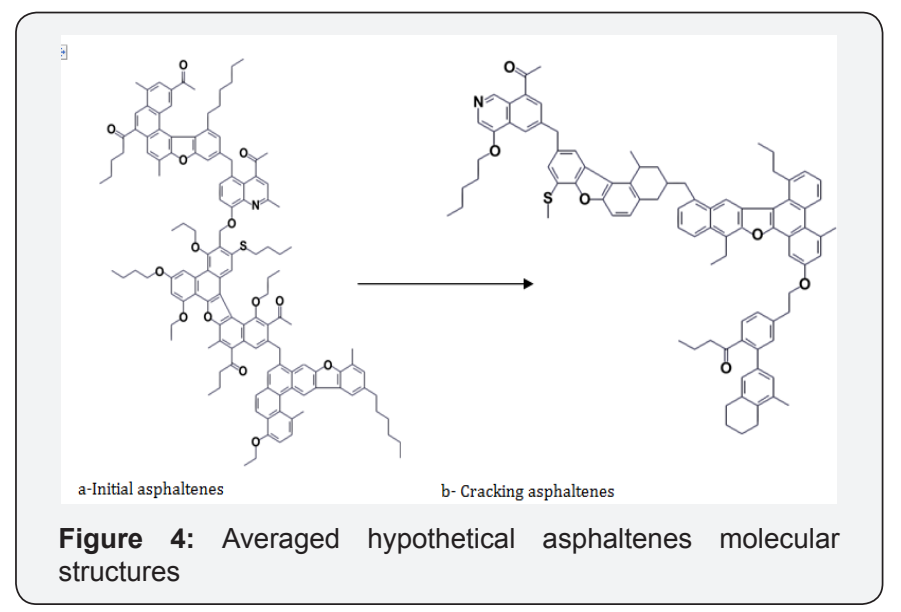

Monte Carlo method was used to construct the molecular structure of macromolecular compounds. This method is used in cases where it is impossible to obtain accurate information about the structure of the chemical compound, or when there are many possible embodiments of structures of a class of compounds, such as asphaltenes. Constructing molecular structure program is written in Fortran Version 6.6. The developed program for the construction of molecular structure used as input parameters analytical data and calculated using the structural-group analysis, which describes the structural fragments of average molecular structure tars and asphaltenes. In the constructing program expanded polycyclic structures library, which used in the construction of high molecular weight components of bitumen by comparison with similar published scientific literature procedures and has been included distribution of hetero atoms into functional groups of molecules. The input parameters are the analytical data obtained from elemental analysis, $1 \mathrm{HNMR}$ spectroscopy, molecular weight of tars and asphaltenes (Figures $4 \& 5)$.

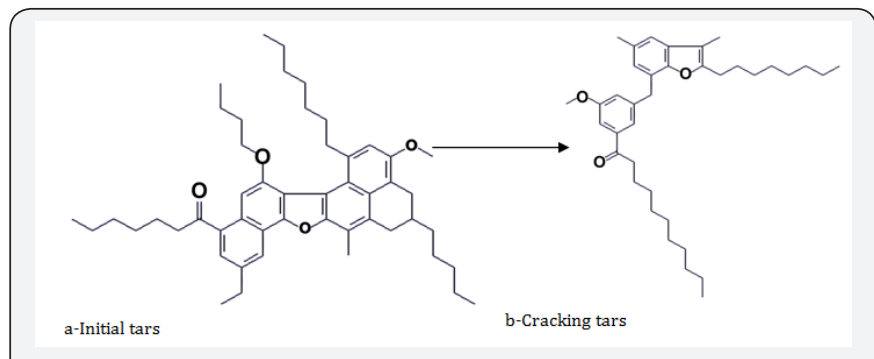

Figure 5: Averaged hypothetical tars molecular structures.

1HNMR spectroscopy (Table 3) was employed to characterize aromaticity of hydrocarbons and to measure the inside changing of molecules. From the results of $1 \mathrm{H}$ NMR the aromatic carbon content was the key structural information. The feed asphaltenes and tars contained about 14.28 and 4.82 wt. \% aromatic carbon, respectively, which was consistent with high content of coke. The easily reacted side chains attached to aromatics and sulfides would be cracked and evolved as gases which reduced hydrogen content (Table 2). In contrast, the aromatic compounds were intact and preserved in the course of thermal cracking, except for the significant yield of coke. The net concentration of aromatics in liquid product kept going higher with removal of aliphatic as fragments in the gas fraction. Aromatics in liquid product can be created either from naphthenes or side chains in aromatic bitumen. The olefins from cracked side chains can build aromatics by free-radical additions followed by rearrangements [8-11].

Table 3:PMR results of macromolecular compounds.

\begin{tabular}{|c|c|c|c|c|}
\hline \multirow{2}{*}{ Sample } & \multicolumn{4}{|c|}{ 1HNMR Results, Wt. \% } \\
\cline { 2 - 5 } & H(Aromatic) & H(CH3) & H(CH2) & H(CH) \\
\hline Initial asphaltenes & 14.28 & 24.97 & 45.94 & 14.81 \\
\hline $\begin{array}{c}\text { Cracking } \\
\text { asphaltenes }\end{array}$ & 14.75 & 24.63 & 50.19 & 10.43 \\
\hline Initial tars & 4.82 & 14.41 & 67.21 & 13.56 \\
\hline Cracking tars & 7.45 & 14.88 & 63.29 & 14.38 \\
\hline
\end{tabular}

The calculations data determined the most stable conformation of tars and asphaltenes molecules. It was found that the stability of the molecules affect structural characteristics such as the number of structural blocks, their size and spatial arrangement of atoms with respect to each other. Consisting of more structural blocks of smaller size molecules are more thermodynamically stable in compared with mono block structure. Molecules which constituting the burst structure are the thermodynamically more stable than a non-layered structures.

\section{References}

1. EbrahimiS, Moghaddas JS, Razavi Aghjeh MK (2008) Study on thermal cracking behavior of petroleum residue. Fuel 87(8-9):1623-1627.

2. Levent A, Yan S, Yoshihisa H, Masahiro H, Satoru M, et al. (1999) Structure and Reactivity of Petroleum-Derived Asphaltene. Energy \& Fuels 13(2): 287-296. 
3. Derek DL, Michael L (2014) Chemical compositions of improved model asphalt systems for molecular simulations. Fuel 115: 347-356.

4. Alexandre TC (2006) NMR and FTIR Characterization of Petroleum Residues: Structural Parameters and CorrelationsJ. Brazil Chem Soc 17(6): 1181-1185.

5. Krivtsov EB, Sviridenko NN, Golovko AK (2013) Indicated cracking of natural bitumen to increase the yield of distillate fractions Izves. Tomsk. Politekh. Univer 323(3): 37-42.

6. Ongarbayev YK, Golovko AK, Krivtsov EB, Imanbayev YI, Tileuberdi E, et al. (2016) Thermocatalytic Crackingof the Natural Bitumens of Kazakhstan. Solid Fuel Chemistry 50(2): 81-87.

7. Kamyanov VF, Bolshakov G F (1984) Neftekhimia, Nauka Press Moscow.
8. Tileuberdi Ye, Ongarbayev Ye, Imanbayev Ye, Mansurov Z, Tuleutaev B et al. (2015) Catalytic Hydrogenation of Oil Sand's Natural Bitumen. Applied Mechanics and Materials (799-800): 77-81.

9. Sultanov FR, Tileuberdi Ye, Ongarbayev Ye K, Mansurov ZA, Khaseinov KA et al. (2013) Study of Asphaltene Structure Precipitated from Oil Sands. Eurasian Chemico-Technological Journal 15(1): 77-81.

10. Gray Murray R (2015) Upgrading Oil sands Bitumen and Heavy Oil, The University of Alberta Press, Alberta.

11. Woods JR, Pleizier GP, Kotlyar LS, Sparks BD, Adjaye J, et al. (2004) Characterization of a coker gas oil fraction from athabasca oil sands bitumen Fuel 83: 1907-1914.

\section{Your next submission with Juniper Publishers} will reach you the below assets

- Quality Editorial service

- Swift Peer Review

- Reprints availability

- E-prints Service

- Manuscript Podcast for convenient understanding

- Global attainment for your research

- Manuscript accessibility in different formats

( Pdf, E-pub, Full Text, Audio)

- Unceasing customer service

Track the below URL for one-step submission https://juniperpublishers.com/online-submission.php 